\title{
Food Sector New Technologies and Innovations: Priorities for Vector Development
}

\author{
Nikolay Belyaev, and Lyudmila Donskova \\ Ural State University of Economics, 620144 Ekaterinburg, Russia
}

\begin{abstract}
The authors consider the engineering and consumer archetypes of food industry enterprises innovative development. Publication activity testifies the increased interest to food sector innovative development; researchers point that the innovation development drivers are the tools of Industry 4.0 and Agriculture 4.0, many of which are already contributing to the transformation of industry in the world community. The main scientific message of this study is that new technologies and innovations in the food sector should be aimed at solving the global problems of hunger and malnutrition, at the production of high quality and safe food, with an increased focus on conscientiousness towards consumers, society and environment. Since it is the food sector, the main food chain formation entity, is responsible for making decisions regarding the level of the product quality, authenticity, naturalness and safety. The authors also defend traditional technologies that can help build a national food system. Research results can serve to identify target areas for innovative development of the food sector in the new economy and can be useful for the business community as an idea of possible investments.
\end{abstract}

\section{Introduction}

Innovative development is relevant for an industry of any specificity, since it is the basis for the competitive products production. The emergence and development of such global trends as breakthrough technologies and innovations produce tangible socio-economic impact, I. Dezhina and A. Ponomarev [1] underline. And positive expectations formed by new trends serve as a powerful incentive for the initiatives implementation in any area, being an indicator of its state and competitiveness.

Common drivers of innovation for all industries are digitalization and the introduction of Industry 4.0 tools [2, 3]. For modern world food systems that are also entering a fundamentally new stage of technological development, a set of innovative Agriculture 4.0 tools based on the implementation of "smart solutions" is proposed, as indicated in the Report [4].

The food and processing industry is that industry type which has its own characteristics and difficulties in innovative development. It is obvious that increasing production efficiency and strengthening competitive potential is impossible without the introduction of innovations, however, the transition to an innovative path of development largely depends on the industry possibilities of technological modernization, agricultural production intensification and other conditions [5]. 
The issues of innovation and new technologies use in the food industry have recently been actively discussed, it is obvious from the publication activity analysis results. The authors highlighted the Higher School of Economics (Russia) scientists studies, prepared in the form of a report [4], scientific manuscripts of ON. Beketova [6], Nguyen Thi Vinh [3], publications of foreign scientists: J.Toth, I. Ferto [7], K. Firley et al. [8], P. Jackman et al. [9], T. Rudinskaya and E. Kuzmenko E. [10], F. Bader and S. Rahimifard [11], Y. Bouzembrak et al. [12] et al. Presenting scientific reviews and original results in the field of research on new technologies and innovations in the food industry.

The subject of discussion, according to the authors, is alternative views on the new concept of organizing food production, which cast doubt on the possible benefits of the introduction of new technologies and indicate possible negative consequences, for example, the increased influence of hi-tech companies, high costs of implementation, certain technologies unpredictability impact, biosphere and man [13], reflected in a few publications.

The issues that require additional research, according to the authors, are related to the definition of priority areas for the innovative development of food industry enterprises in the global and national dimensions. The scientific idea of our research is that new technologies and innovations in the food sector should be directed to the production of high quality and safe products, with an increased focus on the issues of conscientiousness to consumers, society and the environment and to ensure business profit. Out of the four archetypes formulated in [14]: efficiency, engineering, consumer and scientific, engineering and consumer archetypes are analyzed in the global and national food sector development context.

\section{Methods}

In this goal implementation, bibliographic, systemic, logical methods, analysis and synthesis, from the applied methods of publication research and expert assessments were used as theoretical ones.

\section{Results and Discussion}

The food sector, including food products production and the sphere of food supply contribute to the implementation of the most important needs and national interests of any integration community, and the food industry is a strategically important economy sector of any state.

The indicators of the food industry in the Russian Federation are the following: the 3rd place in the industrial production sector structure, revenue over 7 trillion. roubles. (2017), 50 thousand enterprises and 35 subsectors in the structure, the leading of which are the production of meat and meat products $(14 \%)$, the production of dairy products $(14 \%)$ and other subsectors (19\%) [15]. Food production growth at the end of 2019 amounted to $4.9 \%$ in comparable prices, while the production of beverages increased by $3.1 \%$.

At the same time, the Food and Agriculture Organization of the United Nations (FAO) conservatively predicts that if the world population reaches 9.1 billion by 2050 , then world production should grow by $70 \%$, and food production, especially in developing countries, should double [16]. The world must produce food using less energy, fertilizers and pesticides, while lowering greenhouse gas emissions and tackling climate change, making the most of traditional technologies and creating new ones. And these technologies should be used not for the sake of innovation, but to improve and meet the real needs of consumers and reengineer the value chain [5]. 
These technological innovations include the production of genetically modified products obtained by synthetic biology (the most extreme form of genetic engineering). Technological innovations include the production of organic and denominational products, the production and use of food additives, nanomaterials and innovative packaging.

In the global problem context solving the global hunger and malnutrition problem of the population, of course, genetic modification and production of certain types of food are key examples that include cultured meat, milk, egg white and skin, this is advanced genetic engineering. As a technology, it has great potential to meet the food needs of the future, and laboratory meat without a butcher can provide a growing world population with highquality protein, while avoiding many of the environmental and animal protection problems of conventional meat production [17]. However, at the level of the national dimension, for example, in Russia, the perception of "cultured meat" by consumers can be questioned by negative public perception, the same point of view is shared by A. Janet Tomiyama et al. [18].

In many countries, including Russia, the development of high-tech products in biotechnical industry is considered to be a priority. Various groups of governmental, nongovernmental and international organizations have recognized its potential benefits for increasing food production and meeting global food needs by 2050 . The fundamental force that drives the development and implementation of industrial biotechnology is the market economy, since biotechnology promises highly efficient processes with lower operating and capital costs, emphasizes R. S. Singh [19].

The Russian biotechnology market began to form relatively recently - in 2012, and in terms of production volumes it lags behind the world market leaders (USA, countries of the Asia-Pacific region, European countries). The share of the Russian biotechnology market is only $0.1 \%$, the share of the food market is $10 \%$. The basis of the bioindustry in the food industry is the production of food additives and micro-ingredients, classical microbiological technologies are used in brewing, wine-making, bakery and dairy industries [20].

At the level of the world community, innovative technological methods of food processing have been actively developed, aimed at increasing preservation by stabilizing microflora. Among them, the following techniques can be distinguished: processing by high hydrostatic pressure; shock wave treatment to soften the muscle tissue of meat products (tenderization); cold plasma and ozone, which have become effective technologies for the decontamination of freezing foods using electric and magnetic fields, as this is a new technology in the field of refrigeration [21]; freeze-drying (lyophilic) drying, ohmic heating [22], etc. Studies [23] have proven that the known non-thermal technology is high pressure treatment, which since its introduction has had limited application, mainly due to the high cost of electricity required for this process may be more widely used. The research carried out by the authors of the article expanded the database on the absence of this technology negative effect, taking into account meat products sensory properties and nutritional value.

The authors note that modern food technologies should also be aimed at solving another problem that is widely discussed in the scientific community at various levels. As it has been pointed out in [5], food waste is an inefficiencies evidence of mass market, an environmental threat that does not persist in other industries. Between 33 and $50 \%$ of all food produced in the world is never eaten, and this waste is worth over $\$ 1$ trillion. According to L.V. Donchenko [15], the total amount of waste in food production is 20.5 million tons. In this case, only $36.6 \%$ of the total volume of generated waste is used and neutralized. Meanwhile, 800 million people go hungry every night, and each of them could be fed on less than a quarter of the food that is wasted in the US, UK and Europe every year [5]. Using effective solutions throughout the food chain will help reduce the total amount of food wasted and reduce the tension between production and access to food by harnessing the potential to reduce food loss [24]. High-quality storage, deep processing, modern 
logistics and well-developed infrastructure should become priority projects, since it is they that ensure the delivery of products to the consumer in the most popular form [25]. In [26], researchers emphasize that the need to digitize and transfer big data will lead to better solutions, and, as a result, to increase operational efficiency, reduce costs, risks, flexibility, efficiency and clarity of logistics processes in agricultural enterprises. Accepting Industry 4.0, Slovak enterprises (71.6\%) fully agreed with the use of logistics technology.

The concept of food production today cannot be limited to zero hunger criteria alone. Indicators of balanced, nutritious and healthy nutrition are important as key parameters of the country's economic well-being [27]. This concept is relevant both internationally and nationally.

Russian scientists, A.V. Aleshkov et al [28] systematically describe product innovations aimed at solving this problem. The priority areas are the production of combined, functional and enriched products, specialized products, analogs and substitutes for products, the use of new types of raw materials (for example, deer antlers, scorpion lichen as ingredients in the production of bakery products, etc.) of biologically active additives (BAA).

The increase in meat consumption as a result of population growth has led to an increase in demand for appropriate food (protein) sources, along with the need to properly manage leftovers and reduce food waste. In this regard, the assessment and validation of new technologies that make it possible to turn unused materials, previously considered waste, into high-value products, is of great interest to the industry in today's global framework. P. Paulsen Thoresen [25] examined the potential of microwave, ultrasonic, and high-pressure technologies as strategies for pretreatment, before enzymatic hydrolysis, of mechanically boned chicken residues in order to obtain high-value peptides. As a source of protein, it is possible to use agricultural waste, for example, oilseed meal. P. Manuela et al. explored a novel approach to food fortification using natural deep eutectic solvent (NADES) and cocoa by-products. The results of studies have proven the safety and sensory acceptability of the obtained NADES extracts [29].

To determine the vectors of development of the food industry, it is necessary to take into account the trends that shape the food market.

The demand for high quality food, one of the main trends, is growing worldwide at an unprecedented rate in response to growing health problems and consumer awareness of healthy eating options, emphasized in [30]. At the same time, the problem of the quality and safety of food products is not only not decreasing, but is aggravated by new problem situations. For example, recently, consumers and politicians in Central and Eastern Europe have complained that some food products sold in their regions are of inferior quality compared to those sold under the same brands in Western Europe [31]. This is a new question related to the double quality of food.

Researchers [30] emphasize that, unfortunately, the existing control mechanisms are limited and cannot constantly track all products, which indicates the weakness of the system in relation to counterfeiting, mislabelling of products, especially for new innovative products. The advancement of artificial intelligence (AI) provides an opportunity for the development of these tools that use simple sound vibrations to detect food tampering.

\section{Conclusions}

1. In the global dimension, the key areas of development of the food industry are, of course, technologies for the production and processing of products, aimed at reducing the severity of global problems of hunger and malnutrition of the population of different countries. 
2. The vectors of innovative development in the food sector in the global and national dimensions should be the priorities for the production of high-quality, safe products with the solution of issues of falsification and counterfeit goods.

3. New food technologies developed by manufacturers require the development of confidence in the relevance and quality of innovation. At the same time, the origin, ethics and social responsibility of production, the technologies used, the completeness and transparency of information should become the main principles of business. Social media can play a key role in disseminating information.

4. In the context of the innovative development of the food industry at the national level, it is reasonable to consider target research areas with subsequent solutions in the form of innovative projects, for example, dedicated areas for the production of specialized products, the production of personalized products, deep processing of raw materials and the use of secondary processed products.

5. According to the authors, the production of traditional food products made using traditional food technologies should be preserved at the national level. Since today, replacing traditional technologies with new ones often leads to a decrease in the consumer properties of products, namely nutritional value. It is possible to produce traditional products with improved properties and corresponding growing safety requirements, for example, organic products, hypoallergenic, gluten-free and others.

\section{Acknowledgments}

The authors would like to thank the translator and editor for their professional approach to work, as well as colleagues for their support in the process of working on the manuscript.

\section{References}

1. I. Dezhina, A. Ponomarev, Foresight- Russia, 8(2) (2014)

2. Industry 4.0 Opportunities behind the challenge, Background Paper (2017)

3. Nguen Tkhi Vin, A.P. Garnov, Journal of Economics, Entrepreneurship and Law, 10 (7) (2020)

4. N.V. Orlova, E.V. Serova, D.V. Nikolaev, Innovative development of the agroindustrial complex in Russia, Agriculture 4.0 (2020)

5. M. De Clercq, A. Vats, A.Biel, Agriculture 4.0: The Future of Farming Technology (2018)

6. O.N. Beketova, Regional economics and management: electronic scientific journal, 4(48) (2016)

7. J. Toth, I. Ferto, Agricultural Economics - Czech, 63 (2017)

8. K. Firlej, A. Kowalska, A. Pivovar, Agricultural Economics - Czech, 63 (2017)

9. P. Jackman, H. Penya, R. Ross, Agricultural Engineering International: CIGR Journal, 22, 3 (2020)

10. T. Rudinskaya, E. Kuzmenko, Agris online Papers in Economics and Informatics, 11 (4) (2019)

11. F. Bader, S. Rahimifard, Innovative Food Science and Emerging Technologies, 64 (2020)

12. Y. Bouzembrak, M. Klüche, A. Gavai, X. J.P. Marvin, Trends in Food Science \& Technology, 94 (2019) 
13. A.V. Panova, International Research Journal, 7 (97) (2020)

14. Innovation in Russia is an inexhaustible source of growth, McKinsey Innovation Practice (2018)

15. L.V. Donchenko, A. G. Koschaev, R. V. Starshinov, Best Available Technologies. Application in various industries (2017)

16. J. G. Payumo, S. Assem, N. Bhooshan, H. Galhena, R. Mbabazi, K.Maredia, The Open Agriculture Journal, 12 (2018)

17. N. Stephens, L. Di Silvio, I. Dunsford, M.Ellis, A. Glencross, A. Sexton, Trends in Food Science \& Technology, 78 (2018)

18. A. Janet Tomiyama, N. Stephanie Kawecki, D. L. Rosenfeld, J.A. Jay, D. Rajagopal, A. C. Rowat, Trends in Food Science \& Technology, 104 (2020)

19. R. S. Singh. In book: Advances in Industrial Biotechnology, New Delhi, Banglore, (2014)

20. I.P. Belikova, A.H. Tambiev, In book: Socio-economic aspects of management in the era of digital technologies development: materials of the All-Russian (national) scientific and practical conference (2020)

21. Y. Tao, D. Sun, E. Hogan, A. L. Kelly. Emerging technologies for food processing (2014)

22. R. Silva, R.S. Rocha, J.T. Guimarães, C. F. Balthazar, Innovative Food Science \& Emerging Technologies, 65 (2020)

23. F. Cacace, E. Bottani, A.Rizzi, G. Vignali, Food Science \& Emerging Technologies, 60 (2020)

24. FAO. Global food losses and food waste - Extent, causes and prevention (2011)

25. P. Paulsen Thoresen, R. García Álvarez, M. Risa Vaka, T. Rustad, Innovative Food Science \& Emerging Technologies, 64 (2020)

26. A. Dupal, P. Richnák, L. Szabo, K. Porubanová, Agricultural Economics - Czech, 65 (2019)

27. V.G. Gusakov, A.V. Pilipuk, Food industry: science and technology, 4(34) (2016)

28. A.V. Aleshkov, T.K. Kalenik, E.V. Motkina, Bulletin of Kamchatka State Technical University, 36 (2016)

29. P. Manuela, S. Drakula, G. Cravotto, R. Verpoorte, Innovative Food Science \& Emerging Technologies, 66 (2020)

30. G. Iymen, G. Tanriver, Y. Ziya Hayirlioglu, O. Ergen, Innovative Food Science \& Emerging Technologies, 66 (2020)

31. R. Sisto, G. Pellegrini, P. La Sala, Agricultural Economics - Czech, 65 (2019) 